\title{
TWENTY-FIVE YEARS OF LANDSAT THERMAL BAND CALIBRATION
}

\author{
Julia A. Barsi ${ }^{a}$, Brian L. Markham ${ }^{b}$, John R. Schott ${ }^{c}$, Simon J. Hook ${ }^{d}$, Nina G. Raqueno \\ ${ }^{a}$ SSAI, NASA/GSFC, Greenbelt MD 20771; ${ }^{b}$ NASA/GSFC, Greenbelt MD 20771; ${ }^{\circ}$ Center for Imaging \\ Science, Rochester Institute of Technology, Rochester NY 14623; 'NASA/JPL, Pasadena CA 91109
}

\begin{abstract}
Landsat-7 Enhanced Thematic Mapper+ (ETM+), launched in April 1999, and Landsat-5 Thematic Mapper (TM), launched in 1984, both have a single thermal band. Both instruments' thermal band calibrations have been updated previously: ETM+ in 2001 for a pre-launch calibration error and TM in 2007 for data acquired since the current era of vicarious calibration has been in place (1999). Vicarious calibration teams at Rochester Institute of Technology (RIT) and NASA/Jet Propulsion Laboratory (JPL) have been working to validate the instrument calibration since 1999. Recent developments in their techniques and sites have expanded the temperature and temporal range of the validation. The new data indicate that the calibration of both instruments had errors: the ETM+ calibration contained a gain error of $5.8 \%$ since launch; the TM calibration contained a gain error of 5\% and an additional offset error between 1997 and 1999. Both instruments required adjustments in their thermal calibration coefficients in order to correct for the errors. The new coefficients were calculated and added to the Landsat operational processing system in early 2010. With the corrections, both instruments are calibrated to within $\pm 0.7 \mathrm{~K}$.
\end{abstract}

Index Terms - Landsat, Calibration, LWIR, Thermal, $\mathrm{ETM}+, \mathrm{TM}$

\section{INTRODUCTION}

The two Landsat satellites still in operation together have been operating for over twenty-five years. Landsat- 5 and Landsat-7 have been actively acquiring data of the earth's surface since 1984 and 1999, respectively. The instruments both have a suite of visible and short-wave infrared channels, in addition to having a single thermal band each. The resolution of the reflective bands of the instrument are all $30 \mathrm{~m}$, except for the panchromatic band on Landsat-7, which has $15 \mathrm{~m}$ resolution. The thermal bands have a resolution of $120 \mathrm{~m}$ on Landsat- 5 and $60 \mathrm{~m}$ on Landsat-7. The calibration of the Landsat-7 imager, the Enhanced Thematic Mapper+ (ETM+), has been well monitored since launch but the calibration of the Landsat-5 imager, the Thematic Mapper (TM) had not been, until the Landsat-7 calibration team began working with TM. The reflective band calibration is covered in other publications; this paper will focus entirely on the calibration of the thermal bands on both the TM and the ETM+ instruments.

\section{INTERNAL CALIBRATION}

Both Landsat thermal bands are calibrated by a similar calibration mechanism and algorithm. The internal calibrator consists of a single on-board cavity blackbody and a black highly emissive shutter. The shutter sweeps across the optical axis while the scan mirror is reversing direction. These two targets allow for a two-point calibration every scan of the scanning mirror. The temperatures of the blackbody, shutter and other components used in the calibration are downlinked with the housekeeping data.

The calibration equations, though not identical for the two instruments are similar in nature; linear equations with a gain based on the temperatures of the blackbody and shutter and an offset which uses some instrument temperatures, but is based heavily on coefficients determined during pre-launch testing. See [1] for a more complete explanation of the calibration equations.

The internal calibration of the ETM+ has been stable for it's lifetime, changing less than $0.1 \%$ per year since launch. The instrument offset has been stable to within $\pm 0.1 \%$.

The TM suffers from a build-up of a contaminant, probably ice, on the Dewar window, with attenuates the signal reaching the detectors. The contaminant can be removed with an instrument maneuver, but while the ice is building up, the responsivity of the instrument decreases, at times decreasing by as much as $20 \%$. As a result, the gain and offset of the instrument have never been stable. However, since the internal calibration system is used to calibrate the thermal band, the changing responsivity is accounted for in the calibration processing.

\section{VICARIOUS CALIBRATION}

\subsection{NASA/Jet Propulsion Laboratory}


NASA/Jet Propulsion Laboratory (JPL) has operated four buoys on Lake Tahoe on the California/Nevada border since 1999 for the purpose of thermal calibration [2]. The high altitude lake is an ideal thermal calibration target; there is little atmosphere above the lake, the lake is extremely deep so does not freeze in the winter and it has a fairly broad annual temperature range from about $4 \mathrm{C}$ to $20 \mathrm{C}$. The four buoys acquire surface radiance and temperature measurements every few minutes and send the data to JPL via cell phone. The JPL team has also installed a similar station on the Salton Sea, which has reliably been collecting data for the past several years. Though not as ideal a target since the Sea is below sea level and the atmosphere is generally quite thick, the water does get up to $35 \mathrm{C}$ in the summer, so provides a hot target without having to use land. In 1999 and 2000, JPL made several collects on a hot desert, Railroad Valley in Nevada. However, regular collects of the site have not been made since due to the difficulty of the collection and the increased uncertainty in the measurements.

\subsection{Rochester Institute of Technology}

The Rochester Institute of Technology (RIT) team makes use of the local Great Lakes for their targets [3]. They deploy in boats on the lakes and bays around Rochester, NY and Buffalo, NY to measure surface temperatures. The lakes do freeze but RIT collects data from about $4 \mathrm{C}$ to $25 \mathrm{C}$. Recently, RIT has begun using the National Data Buoy Center (NDBC) archive to expand their reach, both in space and time [4]. Using water temperatures collected by open water buoys in Lake Huron, Lake Superior, and off the coast of Delaware, and corresponding atmospheric data acquired near shore, the same techniques are used to predict satellitereaching radiance for the NDBC buoys as for the manually collected temperatures. The buoy method has been found to be as accurate as their traditional method (not statistically different at the $99 \%$ confidence level). Since the water temperature archive is available for the lifetime of Landsat5 , the team was able to extend the calibration back to years before rigorous calibration monitoring started.

\section{LANDSAT-7 ETM+}

\subsection{Calibration History}

The vicarious calibration teams from RIT and JPL discovered shortly after launch that the ETM+ thermal band had a significant calibration error. The $0.31 \mathrm{~W} / \mathrm{m}^{2} \mathrm{sr} \mu \mathrm{m}$ offset error was corrected in 2000 for all ETM+ data acquired since launch by modifying a calibration coefficient in the processing system. In the first two years of the postlaunch vicarious calibration program, JPL made measurements of hot desert pavement (40-55C) at Railroad Valley. These data were considered in the initial calibration correction but because of the uncertainty on the hottest points was high enough that the slope was not statistically different than unity, only an offset correction was implemented.

\subsection{Current Correction}

Regular monitoring has continued since the 2000 calibration correction was issued. The addition of the warm Salton Sea data from 2007-2009 has made a gain error apparent, even though the early Railroad Valley data are no longer considered in the dataset. The compiled RIT and JPL data from 1999-2009 are shown in Figure 1. If the data were perfectly calibrated, the data would be scattered about the 1:1 line. These data are tilted with respect to the 1:1 line, indicating the error is dependent on target temperature. The RIT data are separated into two series: RITG is the traditional Ground truth method involving deploying boats on the lakes; RITB is the new Buoy method with makes use of the NDBC buoys. The results of the teams' compiled

Figure 1. Landsat-7 ETM+ vicarious calibration results for 1999-2009. The data from the four different methods are tilted about the 1:1 line, indicating the instrument has a calibration gain error. The University of Valencia data were not used as part of correction, but are shown here to validate the methods of the two ETM+ calibration teams.

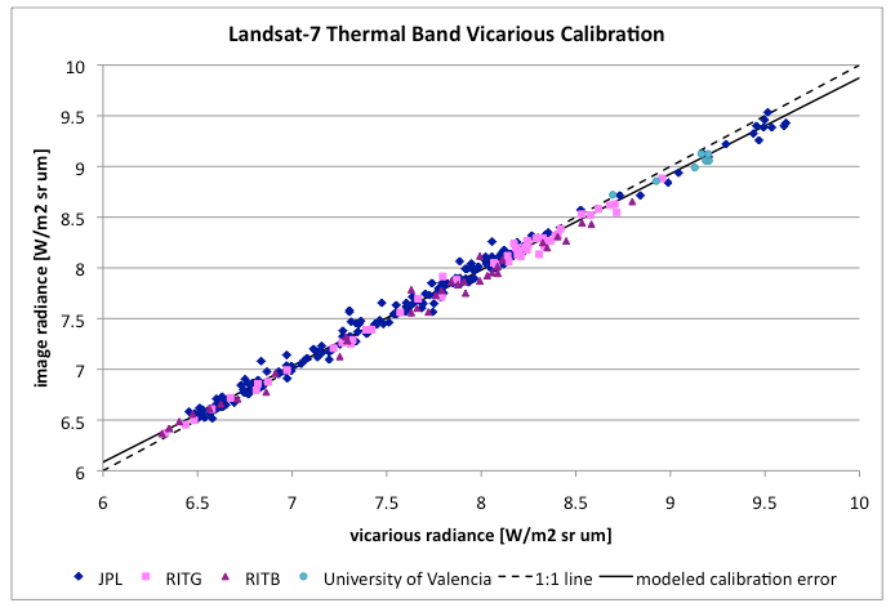

Table 1. Estimated calibration error in brightness temperature of the ETM+ thermal band due to the $5.8 \%$ gain error. This error was corrected in the USGS processing system on Jan. 1, 2010 so data processed after this data will not contain this error in temperature.

\begin{tabular}{|lrr|}
$\begin{array}{c}\text { Target } \\
\text { temperature }\end{array}$ & $\begin{array}{c}\text { Approximate } \\
\text { Radiance } \\
\left(\mathbf{W} / \mathbf{m}^{2} \mathbf{s r} \boldsymbol{\mu m}\right)\end{array}$ & $\begin{array}{c}\text { Estimated } \\
\text { Calibration Error } \\
(\mathbf{K} \text { at 300K) }\end{array}$ \\
\hline $273 \mathrm{~K} / 0 \mathrm{C}$ & 6.0 & 0.8 too hot \\
\hline $285 \mathrm{~K} / 12 \mathrm{C}$ & 7.5 & 0 \\
\hline $300 \mathrm{~K} / 27 \mathrm{C}$ & 9.0 & 0.7 too cold \\
\hline
\end{tabular}


vicarious calibration data indicate a $5.8 \%$ gain error in the ETM+ thermal band calibration for the life of the mission. As a result of the 2000 calibration correction, the calibration error is smallest at the center of the combined temperature range (4-20C). The errors get larger away from the center of the range. Since the noise in this process is $\pm 0.6 \mathrm{~K}$, this error was difficult to detect until the Salton Sea data were added to the collection. The Salton Sea data are all at the high end of the range; all of the JPL data shown in Figure 1 above $8.5 \mathrm{~W} / \mathrm{m}^{2}$ sr $\mu \mathrm{m}$ are Salton Sea acquisitions. These new data made the slope of the regression statistically different than 1, indicating a lifetime gain error. The gain error results in a calibration error that is dependent on target temperature. The approximate error, calculated in radiance but represented here in brightness temperature (at $300 \mathrm{~K}$ ) as a result of this calibration error, is given in Table 1.

An independent validation of the calibration was undertaken by the University of Valencia between 2004 and 2007 [5]. Their results, published this year, agree with the assessment of JPL and the Salton Sea vicarious data; that for higher temperature targets the instrument is predicting a temperature that is too low. While the Valencia results are not used in the final assessment of the error, they are presented here as a validation of the JPL and RIT calibration team methods.

The Landsat-7 calibration error was corrected in the processing system by changing several calibration coefficients. These changes were made in the system on Jan 1, 2010. Analysis of corrected data indicates no residual gain or offset error to within $\pm 0.55 \mathrm{~K}$.

\section{LANDSAT-5 TM}

\subsection{Calibration History}

Early in the life of Landsat-5, RIT performed the first verification of the thermal band calibration. Conclusions in 1985 were that the TM thermal band was calibrated to within $0.9 \mathrm{~K}$ [6]. Unfortunately, the calibration was not monitored between 1985 and 2001. In 2001, the Landsat-7 vicarious calibration teams began monitoring Landsat-5 as well. RIT deployed regularly under Landsat-5 in the lakes and bays but could only calibration current data. JPL was able to carry the calibration back to 1999 , the beginning of the Lake Tahoe buoy archive. By 2007, enough evidence has accumulated to indicate that there was a calibration error [7]. Both teams' data indicated an offset error, both saying that Landsat-5 was reporting cooler than it should be. In 2007, an update was made to the calibration coefficients to account for a $0.092 \mathrm{~W} / \mathrm{m}^{2} \mathrm{sr} \mu \mathrm{m}$ offset, but only for data acquired since 1999. As there was no vicarious calibration before 1999, it was felt that the prelaunch calibration should be maintained until otherwise invalidated.
Figure 2. Landsat-5 TM vicarious calibration results for 1984-2009. RITB data are split into two series at the point of the apparent offset change in the instrument, in 1997. Both series are tilted about the 1:1 line, but there is a different offset for the two date ranges.

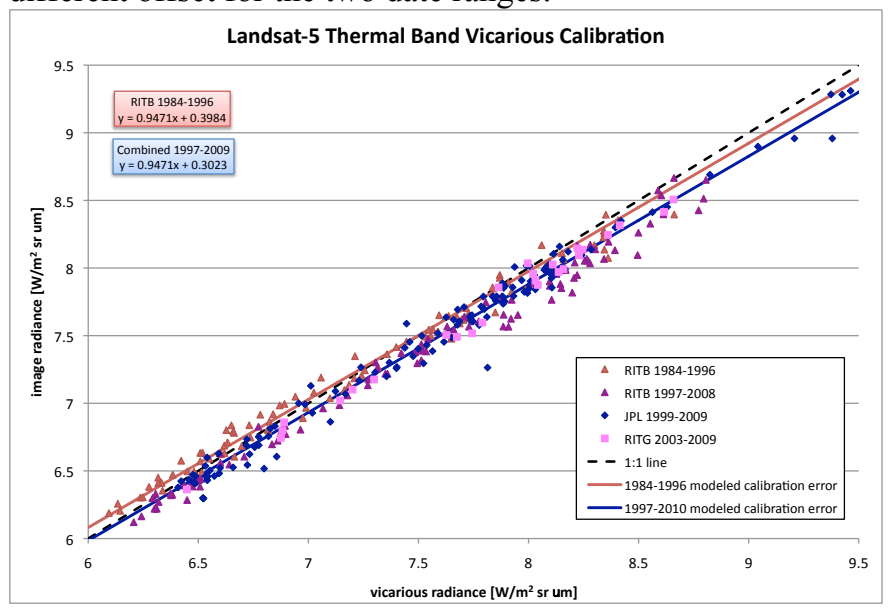

Figure 3. Landsat-5 TM thermal band calibration error based on the vicarious calibration results. The RITB data are the only data covering the lifetime of the TM and until the end of 1996, there is no apparent offset error. Beginning in 1997, the all three datasets agree that there is an offset error of $0.12 \mathrm{~W} / \mathrm{m}^{2} \mathrm{sr} \mu \mathrm{m}$.

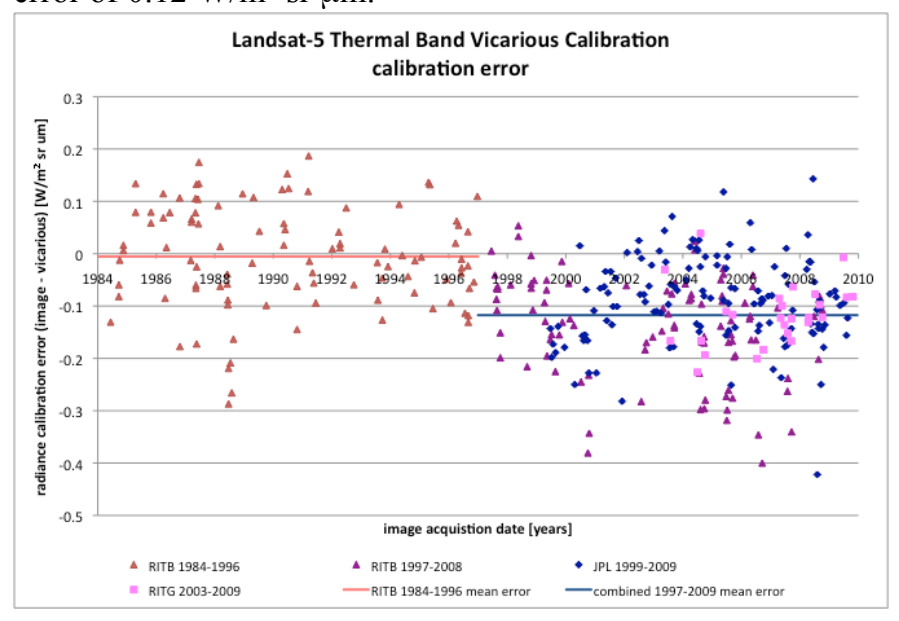

\subsection{Current Correction}

Regular monitoring of the TM thermal band has continued since the error was detected in 2007. The Salton Sea data has also increased the range of temperatures in the vicarious calibration data set, but, more importantly, the RITB has served to increase the temporal range. With the buoys, the calibration history was extended to 1984 instead of ending in 1999. The compiled RIT and JPL are plotted together in Figure 2. The 2007 calibration correction has been removed from the data so that all scenes have been calibrated with the same processing parameters. As with Landsat-7, there is a 
gain error, this time of $5.0 \%$, made most apparent in the high radiance Salton Sea data. Though the buoy data is generally cooler, the gain error is significant in that dataset as well, indicating the gain error has been present since launch.

The change in the instrument offset is more apparent in plot of residual error, where the data are all processed without the 2007 correction (Figure 3). The data acquired before 1997 do not have a statistically significant offset error. However, the mean error in data acquired after 1997 is about $-0.12 \mathrm{~W} / \mathrm{m}^{2} \mathrm{sr} \mu \mathrm{m}$. This indicates that something in the instrument changed in early 1997 , though the change has not yet been tracked back to a specific event. Regardless of what happened in the instrument, it also indicates that the 2007 correction which only affected data acquired after April 1999, needed to be extended back further in time.

The new calibration correction is split into two time periods with the lifetime gain adjustment applied to both time periods: data acquired between launch and the end of 1996 do not require an offset correction; the data acquired starting in 1997 until the present will have a $0.12 \mathrm{~W} / \mathrm{m}^{2} \mathrm{sr}$ $\mu \mathrm{m}$ correction applied. This update makes the largest difference on data acquired in between 1997 and 1999 as the data acquired after April 1999 would have already been corrected for the offset error in the processing system. However, the gain correction is new for all data. The approximate calibration error in brightness temperature at $300 \mathrm{~K}$ due to both the offset and gain errors is given in Table 2.

Table 2. Estimated effect of TM thermal band calibration error present in data products processed after the 2007 calibration update as a result of the lifetime $5.0 \%$ gain error and the later offset error. This error was corrected in the USGS processing system on April. 1, 2010 so data processed after this data will not contain this error in temperature.

\begin{tabular}{crcc}
$\begin{array}{c}\text { Approximate } \\
\text { Target Radiance/ } \\
\text { Temperature } \\
{\left[\left(\mathbf{W} / \mathbf{m}^{2} \mathbf{s r} \boldsymbol{\mu ~ m}\right) /\right.} \\
\mathbf{K} / \mathbf{C}]\end{array}$ & $\begin{array}{c}\mathbf{1 9 8 4 - 1 9 9 6} \\
\text { calibration } \\
\text { error } \\
{[\mathbf{K} \text { at 300K] }}\end{array}$ & $\begin{array}{c}\mathbf{1 9 9 7 - 1 9 9 9} \\
\text { calibration } \\
\text { error } \\
{[\mathbf{K} \text { at 300K] }}\end{array}$ & $\begin{array}{c}\mathbf{1 9 9 9 - 2 0 1 0} \\
\text { calibration } \\
\text { error } \\
\text { [K at 300K] }\end{array}$ \\
\hline $6.0 / 273 \mathrm{~K} / 0 \mathrm{C}$ & 0.68 too hot & -0.19 & 0.87 \\
\hline $6.75 / 279 \mathrm{~K} / 6 \mathrm{C}$ & 0.38 & -0.47 & 0.56 \\
\hline $8.0 / 290 \mathrm{~K} / 17 \mathrm{C}$ & -0.18 & -0.97 & -0.01 \\
\hline $8.5 / 294 \mathrm{~K} / 21 \mathrm{C}$ & -0.39 & -1.16 & -0.22 \\
\hline $10.0 / 306 \mathrm{~K} / 33 \mathrm{C}$ & -1.0 too & -1.71 & -0.85 \\
\hline & cold & & \\
\hline
\end{tabular}

This Landsat- 5 calibration error was corrected by adjusting the calibration coefficients in the processing system on April 1, 2010. Analysis of corrected data indicates no residual gain or offset error for the lifetime to within $\pm 0.67 \mathrm{~K}$.

\section{CONCLUSIONS}

The two operational Landsat instruments continue to acquire daily images covering the globe. Recent advances to the thermal band calibration methodology have revealed that both TM and $\mathrm{ETM}+$ thermal bands had calibration errors, which resulted in a target-temperature dependent error. The errors are within $\pm 1 \mathrm{~K}$ for the lifetime of both satellites over a temperature range of 4-20C. However, the corrections put into the processing system on Jan 1, 2010 for Landsat-7 and April 1, 2010 for Landsat-5 remove this error for all data acquired since the launch of both satellites. With the corrections, Landsat- 7 is calibrated to within $\pm 0.55 \mathrm{~K}$ and Landsat- 5 is calibrated to within $\pm 0.67 \mathrm{~K}$. Users ordering data products from USGS should look for data products that have been processed after these dates to ensure their data are properly calibrated.

\section{REFERENCES}

[1] J.A. Barsi, J.R. Schott, F.D. Palluconi, D.L. Helder, S.J. Hook, B.L. Markham, G. Chander, E.M. O'Donnell, "Landsat TM and ETM+ thermal band calibration," Canadian Journal of Remote Sensing, 29(2), 141-153 (2003)

[2] S.J. Hook, G. Chander, J.A. Barsi, R.E. Alley, A. Abtahi, F.D. Palluconi, B.L. Markham, R.C. Richards, S.G. Schladow, D.L. Helder, "In-flight validation and recovery of water surface temperature with Landsat-5 thermal infrared data using an automated high-altitude lake validation site at Lake Tahoe," IEEE Trans Geoscience and Remote Sensing, 42(12), 2767-2776 (2004)

[3] J.R. Schott, Barsi, J.A., Nordgren, B.L., Raqueno, N.G., de Alwis, D., "Calibration of Landsat thermal data and application to water resource studies," Remote Sensing Environment, 78(1/2), 108-117 (2001)

[4] F.P. Padula, J.R. Schott, "Historic Thermal Calibration of Landsat 5 TM", submitted to Photogrammetric Engineering and Remote Sensing (in press)

[5] C. Coll, Galve, J.M., Sanchez, J.M., Caselles, V., "Validation of Landsat-7/ETM+ Thermal Band Calibration and Atmospheric Correction with Ground Based Measurements" IEEE Trans Geoscience and Remote Sensing, 48(1), 547-555 (2010)

[6] J.R. Schott, "Thematic Mapper band 6, radiometric calibration and assessment," Proc SPIE 924, 72-88 (1988)

[7] J.A. Barsi, S.J. Hook, J.R. Schott, N.G. Raqueno, B.L. Markham, "Landsat-5 Thematic Mapper Thermal Band Calibration Update," IEEE Geoscience and Remote Sensing Letters, 4(4), 552-555 (2007). 